\title{
¿Es posible la comprensión histórica sin anacronismo?
}

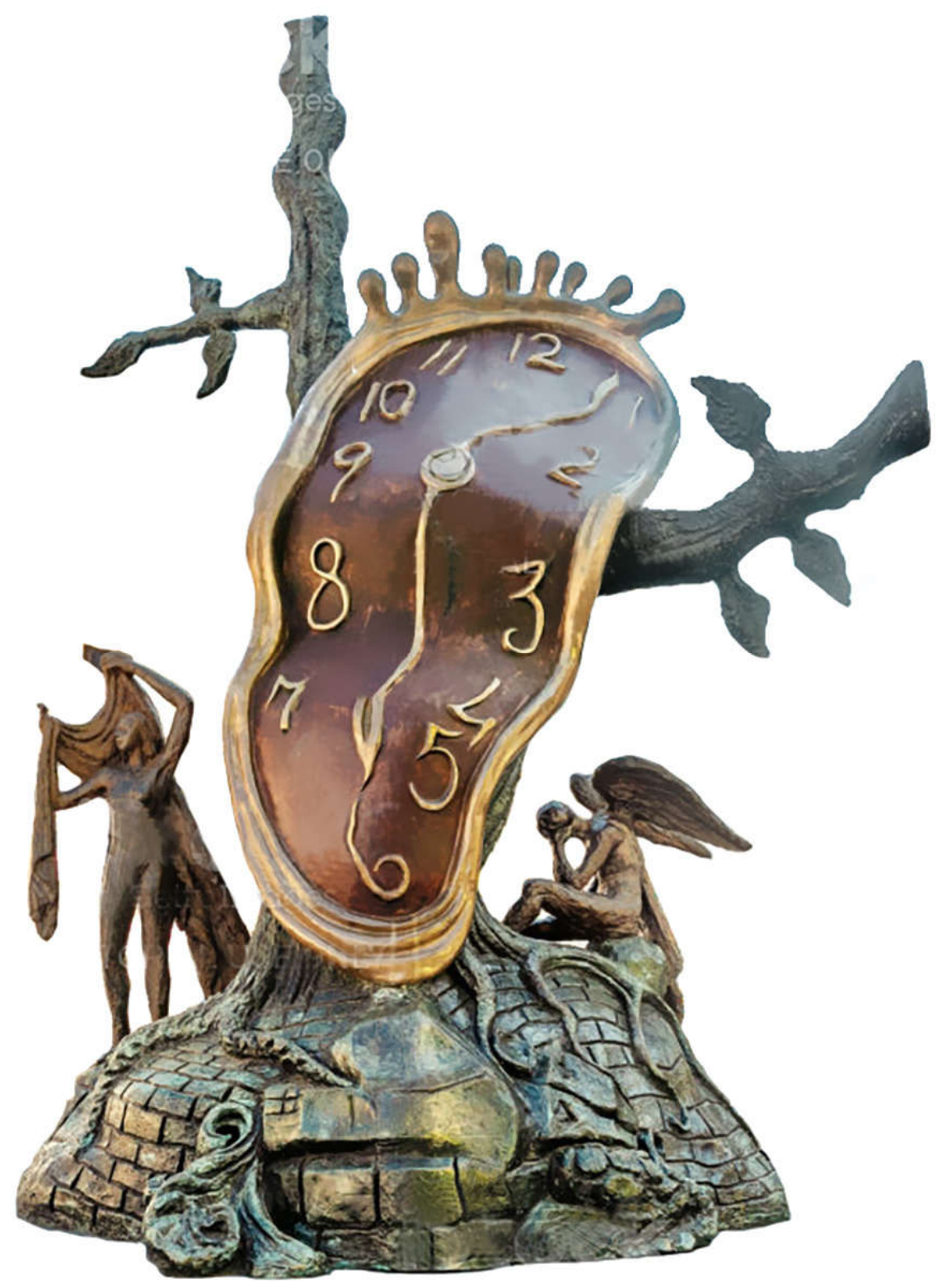

\section{Rosa E. Belvedresi}

Doutora em Filosofia pela Universidad de Buenos Aires (UBA). Professora do Instituto de Investigaciones en Humanidades y Ciencias Sociales (IDIHCS) da Universidad Nacional de La Plata. Pesquisadora do Conicet. Autora, entre outros livros, de La filosofía de la historia hoy: preguntas y problemas. Rosario: Prohistoria, 2020. rosabelvedresi@gmail.com 


\section{¿Es posible la comprensión histórica sin anacronismo?}

Is historical understanding possible without anachronism?

Rosa E. Belvedresi

\section{RESUMEN}

El anacronismo se presenta como un obstáculo a la tarea de la historiadora o historiador que, en el afán por comprender el pasado, debe evitar las intromisiones de elementos que correspondan a una época distinta a aquella de su objeto de estudio, fundamentalmente, aquellos que provienen de su propio contexto. Problema largamente abordado por la teoría de la historia francesa así como por la filosofía y la historia del arte, el anacronismo da cuenta de un problema y a la vez de una condición necesaria. En este trabajo vamos a valorar el papel que juega el anacronismo en la comprensión histórica, para lo cual nos vamos a valer de dos ejemplos: las restituciones de objetos que realizan los museos en respuesta a reclamos de las comunidades originarias y la aplicación de las categorías de análisis que fueron creadas posteriormente a sucesos del pasado a los cuales se pretenden explicar, como es el caso del uso del concepto de "genocidio". Finalizaremos argumentado a favor de la función que el anacronismo tiene para la comprensión del pasado y para iluminar el mundo presente.

PALABRAS CLAVE: anacronismo; comprensión histórica; genocidio.

\begin{abstract}
Anachronism is presented as an obstacle to the task of the historian who, in the effort to understand the past, must avoid interference of elements that correspond to a different time from that of her object of study, fundamentally, those that come from her own context. A problem long addressed by the French theory of history as well as by the philosophy and history of the art, anachronism accounts for a problem and at the same time a necessary condition. In this work we are going to assess the role played by anachronism in historical understanding, for which we are going to use two examples: the restitution of objects that museums make in response to claims of the indigenous communities and the application of the categories of analysis that were created later to events of the past to which they are intended to explain, as is the case of the use of the concept of "genocide". We will finish arguing in favor of the function that anachronism has for the understanding of the past and to illuminate the present world.
\end{abstract}

KEYWORDS: anachronism; historical understanding; genocide.

El anacronismo se define de manera general como una confusión entre épocas, que se produce cuando alguien aplica a un momento o a una persona del pasado una característica que corresponde a otra época. Como es bien sabido, Aristóteles justificaba la práctica de la esclavitud cuando ésta descansaba en ciertas condiciones naturales que diferenciarían a los esclavos de sus amos. Criticar la posición aristotélica sin considerar que, en su época, ella era admi- 
sible, implicaría una interpretación anacrónica. El anacronismo en este caso también involucra una evaluación, negativa, al adjudicar a Aristóteles una idea que es rechazada en la actualidad, pues la esclavitud es considerada inmoral. ${ }^{1}$

El anacronismo suele plantearse como un riesgo o un error. Hay una vinculación estrecha entre esa consideración y el tópico clásico de la teoría de la historia acerca de la necesidad de contar el pasado "tal cual fue", o bien, dejar que el pasado nos hable "en sus propios términos". ${ }^{2}$ De esta manera, se evitaría la contaminación causada por aquellos elementos que pertenecen a otros contextos temporales, y fundamentalmente, a aquellos que corresponden al presente de la historiadora o historiador. El anacronismo sería así un pariente cercano del "presentismo", que diluye los elementos propios del pasado para formular descripciones sobre él en los términos del mundo presente, haciendo desaparecer la diferencia entre ambos: "el presentismo fue considerado la fuente de una representación anacrónica del tiempo histórico debido a decisiones metodológicas erróneas". ${ }^{3}$ Contra un error semejante suele citarse la famosa expresión de Lucien Febvre, según la cual una descripción anacrónica podría decir que César "fue asesinado por un disparo de browning"4, o la afirmación de Bloch: "el anacronismo: el más imperdonable de todos los pecados en una ciencia del tiempo". ${ }^{5}$ Como bien dicen de Mussy y Valderrama al analizar la frase de Febvre, ciertamente "no se pueden introducir elementos de épocas futuras en épocas pasadas". Sin embargo, agregan poco después, "al mismo tiempo un historiador o historiadora no dudaría en afirmar que un análisis de la conjura política en la antigua Roma podría verse beneficiado de los análisis y ejemplos de la conjura política en la época contemporánea" ${ }^{6} \mathrm{La}$ cita nos advierte muy adecuadamente acerca del valor dual que podemos adjudicar al anacronismo. Tanto tiene un aspecto negativo, en cuanto supone el riesgo de subvertir el pasado al mezclarlo con elementos o categorías de otro tiempo; como también posee un aspecto positivo, en la medida en que el presente puede proveernos con estrategias conceptuales que enriquezcan nuestra comprensión histórica.7 Tomado como error o distorsión, el anacronismo difi-

\footnotetext{
${ }^{1}$ Véase ARISTÓTELE. Política: libro I. Madrid: Gredos, 1994.

${ }^{2}$ Nos referimos a la famosa expresión de Ranke en la que rechazaba que la función de la historia fuera juzgar el pasado, en cambio la historia debía mostrar "cómo fue propiamente". Otros historiadores han sostenido que el pasado sólo puede ser entendido desde el punto de vista de sus contemporáneos, como lo expresan las tesis de la revivencia (Nacherleben) de Dilthey o la de la reactualización (re-enactment) propuesta por Collingwood. Véase CARDOSO JR., Helio Rebello. The analytical metaphysics of time and the recent Theory of History: overtones of the debate about resentism. História da Historiografia: International Journal of Theory and History of Historiography, v. 14, n. 35, Ouro Preto, jan.-abr. 2021, p. 154. Disponible en $<$ https://historiadahistoriografia.com.br/revista/article/view/1739>. Consultado el 29 abr. 2021.

${ }^{3}$ CARDOSO JR., Helio Rebello, op. cit., p. 154. Para el análisis del presentismo como un régimen del tiempo, la fuente ineludible es HARTOG, François. Regímenes de historicidad: presentismo y experiencias del tiempo. México: Universidad Iberoamericana, 2007.

${ }^{4}$ FEBVRE, Lucien apud DIDI-HUBERMAN, Georges. Ante el tiempo: historia del arte y anacronismo de las imágenes. Buenos Aires: Adriana Hidalgo, 2011, p. 53.

${ }^{5} \mathrm{BLOCH}$, Marc. Apología para la historia o el oficio del historiador. 2. ed. México: Fondo de Cultura Económica, 2001, p. 163.

${ }^{6}$ MUSSY, Luis de y VALDERRAMA, Miguel. Anacronismo. In: Historiografía posmoderna: Conceptos, figuras, manifiestos. Santiago de Chile: Red Internacional del Libro, 2010, p. 58.

7 Para la defensa del anacronismo, véase LORAUX, Nicole. Eloge de l'anachronisme en histoire. Le Genre Humain, 1, n. 27, Paris, 1993. Disponible en <https://www.cairn.info/revue-le-genre-humain-1993-1-page23.htm>. Consultado el 13 abr. 2021. El análisis clásico de la influencia de puntos de vista anacrónicos sobre
} 
culta nuestra comprensión del pasado ya que puede producir descripciones falaces que no se correspondan con los hechos que se buscan estudiar. Obviamente, no había pistolas browning en la época de César y afirmar su incidencia en su muerte es una falsedad que no debe ser tolerada. El ejemplo de Aristóteles nos ilustra acerca de las condiciones histórico-sociales de su teoría ética al mostrar la dependencia que mantenía con el sentido común de la época, que aceptaba (o al menos toleraba) la esclavitud. Pero nada nos prohíbe revisar su obra a través del prisma de los desarrollos morales posteriores y señalar críticamente su justificación de la esclavitud, que hoy nos parece inaceptable.

La tesis de entender el pasado en sus propios términos posee una fuerte impronta historicista y remite a la idea de que el historiador debe, de alguna manera, ser capaz de concebir y comprender el pasado según lo harían sus propios contemporáneos. Subyace a esta tesis un supuesto acerca de la existencia sostenida del pasado, al cual de alguna manera sería posible "volver", olvidando el carácter constitutivo que posee la tarea de la historiadora o el historiador cuando estudia e interpreta los rastros que el pasado ha dejado tras de sí. Si bien deben evitarse los riesgos de lo que LaCapra denominaba "constructivismo radical", es necesario recordar que las descripciones históricas son siempre resultado de una actividad inferencial, cuyas conclusiones deben ser sometidas al escrutinio intersubjetivo de quienes forman parte de la comunidad académica historiadora: "[l]a historiografía debe verse como una afirmación sobre el pasado [...]. El tipo de justificación cognitiva en historiografía es, por tanto, el de la afirmación justificada. Esta opinión está de acuerdo con ver a la historiografía como una forma de práctica racional que opera en el dominio de la racionalidad". 8

Es claro que, en cuanto comprensión que siempre actúa de manera retrospectiva, la historiografía involucra un riesgo cierto de contaminación de los conocimientos que tiene a la mano la historiadora o historiador: "[l]os documentos tienden a imponer su nomenclatura; el historiador que los escucha, escribe bajo el dictado de una época cada vez diferente. Pero por otra parte, naturalmente piensa en términos de las categorías de su propio tiempo; por consiguiente, con las palabras que le son propias". ${ }^{9}$ Danto señalaba que una noción tan utilizada en los libros de historia como "anticipar" era el resultado de la vinculación creativa entre dos acontecimientos del pasado que no surge de una simple lectura de los datos empíricos. Esas relaciones se expresan en las denominadas "oraciones narrativas". La frase "Aristarco anticipó a Copérnico" propone una descripción verdadera del pasado que sólo puede haber formulado una historiadora o historiador posteriormente a la existencia de

el pasado corresponde a HARTOG, François. El espejo de Heródoto: ensayo sobre la representación del otro. Buenos Aires: Fondo de Cultura Económica, 2003.

${ }^{8}$ KUUKKANEN, Jouni-Matti. Postnarrativist philosophy of historiography. New York: Palgrave MacMillan, 2015, p. 166 (todas las traducciones de los textos que no estén disponibles en español son nuestras). Veáse también BELVEDRESI, Rosa. E. ¿Hay una objetividad específica para la historia? História da Historiografia: International Journal of Theory and History of Historiography, v. 13, n. 34, Ouro Preto, dez. 2020.

${ }^{9}$ BLOCH, op. cit., p. 153. Véase también GINZBURG, Carlo. Our word, and theirs: a reflection on the historian' craft, today. Cromohs: Cyber Review of Modern Historiography, v. 18, Firenze, 2013. Disponible en <https://oajournals.fupress.net/index.php/cromohs/article/view/6892/6890>. Consultado el 5 jun. 2021. Véase también, traducido para el português, idem, Nossas palavras e as deles: o ofício do historiador na atualidade. ArtCultura: Revista de História, Cultura e Arte, v. 23, n. 42, Uberlândia, jan.-jun. 2021. Disponible en <https://seer.ufu.br/index.php/artcultura/article/view/61847>. Consultado el 4 ago. 2021. 
Copérnico y a la luz de la cual pueda "leer" los rastros históricos. En las oraciones narrativas como la citada, el uso del verbo "anticipó" para dar cuenta de lo que hizo Aristarco no pudo haber sido dicha en su época sino después. ${ }^{10} \mathrm{El}$ argumento de Danto es que los contemporáneos no podrían dar una "descripción completa" de un hecho del pasado, y que tampoco es posible para nadie hacerla (a esa pretensión apuntó su crítica al "cronista ideal"), ya que el pasado está siempre abierto a re-descripciones según cuáles sean los acontecimientos posteriores con los que puedan establecerse relaciones justificadamente razonables. De ahí que: "no ser testigo del hecho no es tan malo si nuestros intereses son históricos". ${ }^{11}$

La condición de antecesor que se aplica a Aristarco es claramente anacrónica, ya que no puede proponerse al momento en el que Aristarco existió o desarrolló su teoría. La relación de anticipación sólo puede proponerse luego de que los dos elementos del pasado mentados en cada parte de una oración narrativa (sean actores, teorías, sucesos) hayan sucedido y expresa una relación anacrónica ya que describe los hechos del pasado en términos que no estaban disponibles al momento de su ocurrencia.

Lo que queremos proponer es que el anacronismo, como intrusión (deliberada y controlada) en la descripción histórica de elementos que no corresponden a la época en la que se ubica el fenómeno bajo estudio, posee un valor positivo. El anacronismo permite enriquecer nuestra comprensión histórica al aplicar al pasado teorías y conceptos que no pertenecen estrictamente a la época bajo análisis y así facilita el establecimiento de relaciones que no están disponibles al momento en el que sucede aquel hecho que estudiamos.

\section{Defensa (pequeña) del anacronismo}

Decíamos antes que, como defecto, el anacronismo se asocia a un error historiográfico, al confundir fechas y juntar actores o circunstancias que no participan del mismo arco temporal. Quien lo cometa sufrirá la crítica de las otras historiadoras o historiadores que señalarán que la interpretación propuesta violenta el principio básico de la realidad histórica: la sucesión cronológica. Pero, si seguimos el análisis de Didi-Huberman, el anacronismo no sería sólo un defecto, un "veneno", puesto que implica al mismo tiempo una paradoja: "se dice que hacer la historia es no hacer anacronismo; pero también se dice que remontarse hacia el pasado no se hace más que con nuestros actos de conocimiento que están en el presente. Se reconoce así que hacer la historia es hacer - al menos - un anacronismo". ${ }^{12} \mathrm{El}$ anacronismo expresa "modos de conexión en la historia" que vinculan "acontecimientos, nociones, significaciones que toman el tiempo al revés, que hacen circular el sentido de una manera que escapa a toda contemporaneidad, a toda identidad del tiempo consigo mismo". ${ }^{13} \mathrm{Si}$ esto es así, lo que el anacronismo introduce es más que una alteración temporal, es "una esquirla de sentido que ilumina un momento históri-

\footnotetext{
${ }^{10}$ Cf. DANTO, Arthur. Analytical philosophy of history. In: Narration and knowledge. New York: Columbia University Press, 1985, p. 156.

${ }^{11}$ Idem, ibidem, p. 152 e 153.

${ }^{12}$ DIDI-HUBERMAN, Georges, op. cit., p. 55.

${ }^{13}$ MUSSY, Luis de y VALDERRAMA, Miguel, op. cit., p. 58.
} 
co determinado" ${ }^{14} \mathrm{El}$ anacronismo también puede producir "la ruptura con tiempo único y lineal, y [generar] modos pluralizadores de racionalidad. Este modo del discurso histórico implica el uso heurístico del anacronismo" ${ }^{15}$

En este punto encontramos el aporte novedoso del anacronismo, pues nos brinda la posibilidad de apelar a marcos y categorías teóricas que no se corresponden con el momento en que los sucesos del pasado ocurrieron. Ello nos da la capacidad de interrelacionar elementos de un modo que puede alterar o invertir la sucesión cronológica. De esta manera se iluminan aspectos y dimensiones del pasado a los que no prestaríamos atención por considerar que no son "propios" de la época (por ejemplo, la consideración de los esclavos, para retomar el ejemplo de Aristóteles).

Al pasar el análisis del pasado (en verdad la interpretación de los registros variados que nos han quedado de él) a través del tamiz de las categorías que tenemos ahora disponibles (tales como las relaciones de género, la estructura de clases, las ideas científicas con las que contamos, etc.), logramos una descripción que es histórica en dos sentidos: porque nos presenta el pasado histórico y porque expresa el punto de vista (histórico) desde el cual damos cuenta del pasado. Reconocer la historicidad de nuestro punto de vista es, también, asumir su contingencia y por ello, la necesidad de su constante justificación racional frente a quienes puedan disputarla. Todo esfuerzo de comprensión histórica es necesariamente retrospectivo y, por lo tanto, no puede ser inmune a la intromisión de elementos que corresponden a épocas posteriores o a aquella desde la cual intentamos comprender el pasado. ${ }^{16}$

Dos análisis históricos pueden ayudarnos a clarificar nuestra posición. En el estudio que Koselleck le dedica a las variedades de la experiencia histórica, identifica un tipo de experiencia que, dice, sólo es accesible a través de la investigación histórica pues corresponde a fenómenos de larga duración cuyas significaciones se les escapan a los actores históricos. Si bien son fenómenos que impactan en las experiencias de los sujetos, sólo podríamos ser "conscientes [de ellas] gracias a la investigación histórica". Se trata de aquellos procesos y cambios históricos diacrónicos - como "el surgimiento del sistema económico mundial" - que se inscriben "en secuencias que rebasan a una sola generación y escapa[n] a la experiencia inmediata". Esa experiencia "histórica" en sentido estricto "no es en absoluto perceptible sin los métodos historiográfi$\cos ^{\prime \prime} .{ }^{17}$ Según Koselleck, sin ese conocimiento, que es posterior y que vincula los sucesos de una época con un panorama temporal más amplio - inaccesible a los actores históricos -, no podríamos dar cuenta de los cambios en sus percepciones y experiencias. La historiografía propone así una interpretación anacrónica, reveladora de la compleja conformación de la realidad en la que esos actores históricos han debido actuar. Hemos logrado producir un des-

\footnotetext{
${ }^{14}$ Idem, ibidem, p. 59.

${ }^{15}$ DOSSE, François. De l'usage raisonné de l'anachronisme. Espaces Temps, n. 87-88, Lyon, 2005, p. 13. Disponible en <https://www.persee.fr/doc/espat_0339-3267_2005_num_87_1_4372>. Consultado el 19 mayo 2021.

${ }^{16}$ Véase MITROVIĆ, Branko. Attribution of concepts and problems with anachronism. History and Theory, $\mathrm{n}$. 50, Middletown, oct. 2011, p. 310 e 311.

${ }^{17}$ KOSELLECK, Reinhardt. Cambio de experiencia y cambio de método. Un apunte histórico-metodológico. In: Los estratos del tiempo. Barcelona: Paidós, 2001, p. 52-55.
} 
cripción del pasado que apela a conceptos y categorías de la ciencia histórica pero que son extraños para los actores y la época que procuramos estudiar.

El otro ejemplo que puede sernos de utilidad lo podemos encontrar en los análisis que la historiadora feminista Joan W. Scott realiza sobre el modo en que el feminismo construye la identidad femenina. Según Scott, el feminismo provee una línea identitaria que responde más a una fantasía que a la pura constatación de detalles históricos. Crítica de la noción de identidad, Scott afirma que ella no preexiste a los usos que los actores históricos (en este caso, las feministas) hacen de ella sino que resulta de una construcción retroactiva al servicio de los intereses políticos que movilizan a esos actores. Pensar la identidad femenina como una fantasía (con sus ecos que la replican de manera incompleta o deforme en distintas épocas) le permite a Scott mostrar "cómo algunos movimientos políticos usan la historia para solidificar la identidad y por lo tanto construyen distritos que cruzan los límites de la diferencia que separa a las mujeres físicas una de la otra, dentro de las culturas, entre las culturas, y a través del tiempo". ${ }^{18}$ La historiografía feminista, a su vez atada al movimiento feminista al que provee de una tradición, adopta esas continuidades porque proporcionan "una base común". ${ }^{19}$ De modo que, tanto el esfuerzo historiográfico por hacer historia de las mujeres, como el feminismo en cuanto movimiento político, apelan a una construcción de continuidades que podríamos considerar, a los fines de nuestro argumento, anacrónicas, en cuanto son construidas con posterioridad a los hechos y a las personas que son objeto de estudio. Esa construcción, expresada en las figuras de la oradora o la madre, es en cierta medida extraña a aquellas mujeres a quienes se aplica, pues resulta de la eficacia de la fantasía de quienes la necesitan para darse un sentido histórico.

En lo que sigue, vamos a argumentar a favor de la utilidad del anacronismo para la comprensión histórica. Nuestros análisis van a exceder el plano del interés puramente historiográfico, pues nos proponemos elucidar los usos del anacronismo en la reparación de las injusticias del pasado. Para ello vamos a analizar con detenimiento dos casos en los que consideramos que el anacronismo es una condición necesaria para la comprensión del pasado y para la reparación de la injusticia.

\section{Dos apuestas anacrónicas}

a) Una visita al museo histórico.

Los museos históricos representan un ejemplo vivo y manifiesto del anacronismo. Las piezas se exhiben distribuidas en cubículos transparentes, dispuestas en un orden y bajo un sistema de luces que difícilmente sean aquellos correspondientes al momento de su existencia original. A ello se suma la disposición de carteles explicativos que incluyen descripciones de los objetos que las y los visitantes pueden ver, su posible datación histórica y a veces un mapa que indica el sitio de su posible procedencia. Pueden recorrerse distintas épocas y geografías con sólo caminar unos metros y pasar a la próxima sala o,

${ }^{18}$ SCOTT, Joan Wallach. The fantasy of feminist history. Durham \& London: Duke University Press, 2011, p. 66.

${ }^{19}$ Idem, ibidem, p. 57. 
a veces, al próximo exhibidor transparente ubicado en la misma sala, a escasos pasos de distancia. Una vez que entramos al museo, nos deshacemos de nuestros bolsos y mochilas e ingresamos a un espacio que se presenta como "del pasado", traído hasta nosotros para que podamos explorarlo en un viaje fantástico, al final del cual recuperamos nuestras pertenencias y volvemos a la calle, a nuestro mundo actual. El pasado que exhibe el museo nos presenta el mundo de otros (a quienes podemos, o no, aceptarlos como nuestros antecesores). Y hemos llegado a él a través de la puerta del museo que forma parte de nuestro presente. El anacronismo producido por la visita es reforzado por los relatos explicativos que se agregan a las muestras, propuestos como un marco general que guía a las y los visitantes $\mathrm{y}$, más importante, aportan significado a los objetos que se exhiben. Desde restos de piedras con los rudimentos de la escritura, hasta bustos y urnas funerarias nos son presentados como ilustraciones didácticas de un tiempo pasado del cual provienen y en el cual son ubicados según las interpretaciones actualmente aceptadas acerca de sus sentidos, usos y valor. Pero no es este el aspecto anacrónico de los museos históricos que queremos rescatar y que es, evidentemente, inevitable.

Muchas de las piezas que conforman los acervos de museos históricos han sido obtenidas bajo condiciones de opresión política o, directamente, por la fuerza. Esos objetos, separados de su entorno original, son exhibidos ahora en museos enormes de grandes capitales del mundo. En los últimos años se han producido muchos reclamos de restitución de esas piezas para que vuelvan a sus poseedores originarios. ${ }^{20}$ No es nuestro interés entrar en el complejo tema de las restituciones, que tiene aristas que exceden el alcance de este trabajo. Sin embargo, queremos llamar la atención al modo en que los museos responden a esos reclamos.

Vamos a tomar como ejemplo el caso del Museo de Ciencias Naturales dependiente de la Universidad Nacional de La Plata (Argentina). El museo poseía y exhibía objetos e incluso restos mortales pertenecientes a diversas etnias de pobladores originarios de Argentina (y de otras regiones de América y del mundo). Esas piezas tuvieron como destino el museo luego de ser, en muchos casos, saqueadas de los lugares donde se encontraban. Desde hace años, producto de los reclamos realizados por los descendientes de esas etnias, el museo ha restituido piezas y restos humanos, conservando algunas aún en su poder que ya no exhibe. Una primera restitución tuvo lugar en 1994. Se trató de los restos del cacique Modesto Inacayal reclamados por el Consejo Indígena Mapuche con sede en la provincia argentina de Chubut, que demandaba el derecho de poder darle sepultura según sus creencias. Según puede leerse en su página web, a partir del año 2006 el museo generó los protocolos necesarios para atender de manera organizada las demandas de las distintas comunidades que reclamaran la devolución de los restos de sus antecesores y de diversos objetos. Las restituciones que se produjeron tuvieron como marco

\footnotetext{
${ }^{20}$ Un ejemplo reciente de la tramitación de un reclamo de devolución se dio en abril de 2021 cuando Alemania acordó la devolución de los denominados "Bronces de Benín" a las autoridades nigerianas. La restitución tendrá lugar a partir del año 2022 e incluye un conjunto de bustos y esculturas fabricados entre los siglos XVI y XVIII que fueron saqueados por los británicos a finales del siglo XIX y luego adquiridos por los alemanes.
} 
legal la ley 25.517 sancionada en el año 2001 y la Constitución Nacional Argentina según su modificación del año 1994 (artículo 75, inciso 15). ${ }^{21}$

La restitución puede pensarse ella misma como una acción anacrónica. Un primer anacronismo se hace evidente en los registros fotográficos de las restituciones. En ellas puede verse lo que parece ser la mezcla de distintos momentos temporales, manifestados por las variadas indumentarias de los presentes, sus actitudes corporales frente a los restos y los diversos objetos que aparecen en los espacios administrativos del museo (piezas ceremoniales, urnas, la bandera wiphala). ${ }^{22}$

Podríamos ir más lejos y caracterizar a la restitución como el ejercicio de una justicia demorada. La restitución no permite una "vuelta" al pasado tal como éste era originalmente, sino que produce una intervención desde el presente que busca restañar una herida causada con anterioridad. Ese gesto anacrónico exhibe, también, aristas del presente que permanecían ocultas. Por ejemplo, se hace manifiesta la existencia de los continuadores de esas etnias originarias, cuyas vidas transcurren fuera de los museos y de los ámbitos universitarios, en espacios geográficos muchas veces marginados de la vida social y cuya identidad cultural ha sido históricamente negada. ${ }^{23}$ La acción anacrónica involucrada en lo que caracterizamos como justicia demorada, supone tanto un esfuerzo por reparar un daño (ya realizado y como tal imposible de ser deshecho), como hacer evidente el carácter histórico, y por tanto contingente, de la sociedad presente que ha marginalizado esas identidades culturales a las que ahora reconoce. A su vez, tiene un impacto en el conocimiento histórico pues ha obligado a reformular los objetivos del museo en el marco de la función que cumple tanto en la investigación antropológica como en la formación de estudiantes. En su página web puede leerse:

El reclamo de restos humanos por parte de algunas comunidades aborígenes de la Argentina ha dado lugar a modificaciones en las condiciones de conservación y gestión de dichos restos, de acuerdo con la legislación vigente, consideraciones éticas y la política de la institución. Además de restituir los individuos reclamados a sus descendientes, el MLP ha procedido al retiro de los restos humanos correspondientes a los pueblos originarios de la Argentina, de las salas de exhibición. ${ }^{24}$

b) Los usos del concepto de genocidio

\footnotetext{
${ }^{21}$ La restitución de Inacayal y las que le siguieron son descriptas por AMETRANO, Silvia. Los procesos de restitución en el Museo de La Plata. Revista Argentina de Antropología Biológica, v. 17, n. 2, La Plata-Buenos Aires, jul.-dic. 2015. La política asumida por el museo puede leerse en su página web: $<$ https://www.museo.fcnym.unlp.edu.ar/restituciones/restituciones_presentacion-21>.

${ }^{22}$ Resulta inevitable pensar aquí en la figura de la "simultaneidad de lo anacrónico" de Koselleck.

${ }^{23}$ La Constitución Nacional previa a la reforma de 1994 incluía en un inciso de su artículo 67 la afirmación de que era función del Senado de la Nación "[p]roveer a la seguridad de las fronteras; conservar el trato pacífico con los indios, y promover la conversión de ellos al catolicismo".

${ }^{24}$ Este párrafo está disponible en <https://www.museo.fcnym.unlp.edu.ar/restituciones/restituciones_ presentacion-21>. En este link también pueden verse algunas de las imágenes a las que nos referimos antes. En relación con el caso de Alemania mencionado antes, la ministra de Cultura alemana, Monika Grütters, justificaba la restitución de los bronces en estos términos: "[d]e esta manera queremos contribuir al entendimiento y la reconciliación con los descendientes de las personas que vieron expoliados sus tesoros culturales durante la época colonial". Véase la noticia en

$<$ https://www.dw.com/es/alemania-devolver\%C3\%A1-a-nigeria-sus-bronces-de-ben\%C3\%ADn-a-partirdel-a\%C3\%B1o-que-viene/a-57387258>.
} 
El concepto de genocidio fue formulado por Lemkin en 1944 y se utilizó para describir la matanza sistemática perpetrada por los nazis durante la Segunda Guerra Mundial, cuyas víctimas fueron mayoritariamente judías, junto con otras víctimas provenientes de distintos grupos étnicos o sociales (como los romaníes, los enfermos mentales, los homosexuales, entre otros). ${ }^{25}$ Arendt prefirió, en cambio, el uso del término "matanzas administrativas", para dar cuenta de la maquinaria burocrática que se puso en marcha con la finalidad de exterminar y luego hacer desaparecer los restos de millones de personas. Mucho se ha debatido acerca de los usos del término "genocidio" en las explicaciones historiográficas; la misma Arendt dice: "[e]l concepto de genocidio, acuñado con el explícito propósito de tipificar un delito anteriormente desconocido, aun cuando es aplicable al caso de Eichmann, no es suficiente para abarcarlo en su totalidad, debido a la simple razón de que el asesinato masivo de pueblos enteros no carece de precedentes". ${ }^{26}$ Se abría así la discusión acerca del carácter único del extermino nazi en la historia. La denominada "uniqueness" del holocausto fue el eje del debate de fines de los años ochenta e inicios de los años noventa, que se centró en las dificultades que suscitaba la representación de un acontecimiento que se había convertido en el símbolo global del horror. ${ }^{27}$ No es ésa la discusión que nos interesa atender en el contexto de este trabajo, queremos prestar atención a la trasposición del uso del término "genocidio" a otros casos históricos. Nos referimos en particular a las situaciones que involucraron matanzas masivas de grupos sociales antes de la formulación del término, en condiciones completamente diferentes y con la incidencia de actores e instituciones que funcionaron de manera distinta a aquellos que lo hicieron bajo el régimen nazi.

En la discusión sobre el uso de la categoría de "genocidio" se ha insistido en que la ocurrencia previa del asesinato masivo de armenios a comienzos del siglo XX también puede ser caracterizada como tal, según la formulación aceptada en 1948 por la Convención de las Naciones Unidas que tipifica ese delito. Sin duda, pueden encontrarse similitudes entre ambos acontecimientos, así como con otros que sucedieron en la segunda mitad del siglo XX. Pero lo más interesante es la aplicación de la categoría de "genocidio" a otras épocas históricas anteriores, épocas cuya caracterización dista mucho de la situación política de Alemania o del Imperio Otomano en el siglo XX. Para ello, se amplían incluso las connotaciones del término hasta incluir el denominado "genocidio cultural", que permitiría describir las políticas de supuesta asimilación de los individuos provenientes de pueblos originarios a las instituciones y prácticas de las sociedades de ascendencia europea. En ambos casos, el concepto de "genocidio" resulta reformulado para su aplicación a contextos y épocas para los que no estuvo, inicialmente, pensado. En su formulación de 1948, el genocidio era definido como un crimen producido contra un grupo con el fin de lograr su destrucción física parcial o total. El genocidio

\footnotetext{
${ }^{25}$ Véase LEMKIN, Raphael. El dominio del Eje en la Europa ocupada. Buenos Aires: Prometeo, 2009.

${ }^{26}$ ARENDT, Hannah. Eichmann en Jerusalén. Barcelona: Lumen, 1999, p. 419.

${ }^{27}$ Cf. FRIEDLANDER, Saul. En torno a los límites de la representación: el nazismo y la solución final. Buenos Aires: Universidad Nacional de Quilmes Editorial, 2008, y FEIERSTEIN, Daniel. Unicidad, comparabilidad y narración: apuntes sobre método, teoría y política a propósito del genocidio nazi. In: El genocidio como práctica social: entre el nazismo y la experiencia argentina. Buenos Aires: Fondo de Cultura Económica, 2007.
} 
cultural involucra, también, la destrucción deliberada de los valores e instituciones que definen a un grupo particular, con ello se anula la posibilidad de que los sobrevivientes puedan apelar a esos acervos para identificarse: “[a]pesar de su estatus legal ambiguo, el genocidio cultural se está adoptando cada vez más como una forma de conceptualizar la experiencia indígena y como herramienta para la defensa de los derechos humanos". ${ }^{28}$

Para mencionar nuevamente un caso de Argentina, la historiografía reciente ha comenzado a caracterizar como genocidio las prácticas de asesinato y sometimiento que fueron ejecutadas por el estado nacional para afianzar su presencia territorial en la zona sur del país hacia el final del siglo XIX (durante la denominada "Campaña del Desierto"). La consecuencia de las acciones llevadas adelante por el ejército nacional fue la casi total extinción de las etnias que ocupaban el territorio patagónico. Las prácticas violentas sobre la población indígena incluyeron "la eliminación física, la reclusión en campos de concentración, la deportación, la esclavitud, el borramiento de la identidad de los niños y la destrucción cultural". Esos elementos habrían de constituir: "mecanismos que se suman a la conceptualización de este proceso político como genocidio". ${ }^{29}$

Como en el ejemplo que mencionábamos antes, el uso de la categoría expresa también un ejemplo de anacronismo, en la medida en que se aplica a una época y a unos actores históricos muy distintos de aquellos para los cuales fue formulada. Se trata de una época y unos actores que no habrían sido cubiertos por la definición de genocidio antes de que la categoría estuviese disponible y, más aún, hasta que se pudo complejizar su uso diversificando su alcance. Caracterizar como genocidio lo realizado por el ejército nacional cuestiona otra vez la dirección del tiempo. Por un lado, porque obliga a revisar los casos prototípicos en los que se usó esa figura para identificar cuáles son las condiciones que garantizan su aplicación adecuada. Pero también porque, como en el ejemplo anterior, el uso de esta categoría nos permite repensar el presente, descubriendo las circunstancias contingentes de su emergencia. Identificar como genocidio las acciones militares que formaron parte de la denominada "Campaña del Desierto" constituye también un acto de justicia demorada, pues señala que el supuesto "desierto" estaba habitado y que quienes hoy no están allí fueron exterminados.

\section{Anacronismo: una evaluación de sus usos}

En el análisis que hemos llevado a cabo, podemos distinguir dos aspectos del anacronismo que pueden indicar un uso valioso del mismo. En primer

\footnotetext{
${ }^{28}$ La definición de genocidio según la Convención de las Naciones Unidas se establece en el apartado II de dicho documento: <https://undocs.org/pdf?symbol=es/A/RES/260(III)>. La definición de genocidio cultural que citamos corresponde a KINGSTON, Lindsey. The destruction of identity: cultural genocide and indigenous peoples. Journal of Human Rights, v. 14, n. 1, Mansfield, ene. 2015, p. 67.

${ }^{29}$ DELRIO, Walter, LENTON, Diana MUSANTE, Marcelo y NAGY, Mariano. Discussing indigenous genocide in Argentina: past, present, and consequences of Argentinean State policies toward native eoples. Genocide studies and prevention: An International Journal, v. 5, iss. 2, Tampa, 2010, p. 139. Disponible en $<$ https://scholarcommons.usf.edu/gsp/vol5/iss2/3/>. Consultado el 7 abr. 2021. Véase también PÉREZ, Pilar. Archivos del silencio: Estado, indígenas y violencia en Patagonia central, 1878-1941. Buenos Aires: Prometeo, 2016, p. 33-107.
} 
lugar, podríamos decir que la apelación al anacronismo responde a un interés historiográfico pues facilita la comparación entre acontecimientos históricos al permitir tomar de manera más laxa la constricción que impone la cronología. La comparación permite el diseño de estrategias explicativas que dan cuenta de cómo operan factores de diverso tipo y eficacia causal según como se combinan en aquellos contextos en los que pueden identificarse.

En segundo lugar, el anacronismo también puede atender a un interés práctico. En los ejemplos que analizamos, las políticas institucionales de restitución de los museos y la aplicación de la categoría de genocidio, expresan una forma de hacer justicia. Las primeras porque buscan reparar un daño y la segunda, porque que identifica un crimen que estaba silenciado. De nuevo, entonces, el anacronismo puede servirnos como el ejercicio de una forma de justicia que se funda en la alteración de la sucesión temporal y, así, revisa el pasado para poder ejercer alguna reparación desde el presente. Podríamos decir que en el anacronismo se da una re-escritura de la historia que corrige silencios y omisiones, deliberadas o intencionales. En el anacronismo se anuncia, diría Benjamin, la "imagen dialéctica" del pasado que "corre el riego de desaparecer con cada presente que no se reconozca mentado en ella". ${ }^{30}$ Como señala Naishtat: “[s]e trata de la pervivencia del pasado mismo en su anacronismo esencial como potencia de irrupción en el presente". De allí entonces, la potencia del anacronismo para alterar la linealidad temporal, la simple sucesión cronológica, "el anacronismo deviene un rasgo ontológico que hace posible la historiografía misma". ${ }^{31}$

Como hemos señalado, la emergencia del anacronismo en nuestro trato con el pasado resulta inevitable, ya que el pasado es una articulación particular de la información a la que accedemos, la que es tamizada con los dispositivos interpretativos que hemos desarrollado. Estos dispositivos interpretativos provienen del amplio conjunto de teorías que se han desarrollado a lo largo de la historia de la disciplina histórica y no surgen, por así decirlo, del propio pasado ni de los datos que de él tengamos.

Nos parece importante señalar que el anacronismo, aun cuando inevitable, requiere una constante vigilancia epistemológica para evitar simples traslaciones o yuxtaposiciones de marcos conceptuales que operan sin que seamos conscientes de ellos. Como nos advierte Didi-Huberman, el anacronismo "modifica completamente el aspecto de las cosas según el valor de uso que se le quiera acordar. Puede aparecer una nueva objetividad histórica, pero puede hacernos caer en un delirio de interpretaciones subjetivas" ${ }^{32}$ Es impo-

\footnotetext{
${ }^{30}$ BENJAMIN, Walter. Sobre el concepto de historia. In: REYES MATE, Manuel. Medianoche en la historia: comentarios a las tesis de Walter Benjamin. Madrid: Trotta, 2009, p. 107 (tesis V). Como agrega Reyes Mate en el análisis de esta tesis, el historiador para Benjamin "sabe que el pasado no está ahí, sino que ese pasado que él trata de conocer porque es un desconocido sólo está ahí un instante [...] Se trata de salvar ese pasado [...] porque gracias a esa presencia el presente puede saltar sobre su propia sombra, es decir, puede liberarse de la cadena causal que lo trajo al mundo". Idem, ibidem, p. 108 e 109.

31 NAISHTAT, Francisco. Anacronismo y actualización: reflexiones sobre discontinuidad, época y pervivencia (Nachleben) en los conceptos contemporáneos del tiempo histórico. In: BRAUER, Daniel, ACHA Omar, RATTO, Adrián y MARTÍN, Facundo (compiladores). Actas del IV Congreso Internacional de Filosofía de la Historia. Buenos Aires: Teseo, s./a. Disponible en <https://www.teseopress.com/actasivcongreso intfilohistoria/chapter/anacronismo-y-actualizacion-reflexiones-sobre-discontinuidad-epoca-y-pervivencianachleben-en-los-conceptos-contemporaneos-del-tiempo-historico/>. Consultado el 7 abr. 2021.

32 DIDI-HUBERMAN, Georges, op. cit., p. 57.
} 
sible que nos desprendamos de nuestra condición actual, con lo que ella involucra en términos de perspectivas conceptuales y marcos experienciales que forman parte de nuestro "utillaje mental" (la expresión es de Febvre) para comprender el mundo que nos rodea. No hemos hecho aquí una defensa del anacronismo ejercido de manera inconsciente ni de la aplicación imprudente de comparaciones ligeras que traducen el pasado sin más a nuestro presente.

Proponemos un uso del anacronismo que problematice nuestra relación con el pasado. En los ejemplos que analizamos, pueden identificarse hilos que cruzan la distancia temporal y tejen continuidades. Pero esas continuidades no son lineales ni evidentes. Son construidas para salvar la distancia temporal y para hacer posible alguna intervención reparadora. El anacronismo tal como lo hemos defendido en este trabajo hace posible reconocer el carácter contingente del pasado y, así, del presente desde el cual nos hemos impuesto la tarea de estudiarlo.

Artigo recebido em 4 de setembro de 2021. Aprovado em 17 de outubro de 2021. 